\title{
DUZENTOS ANOS DE LITERATURA BRASILEIRA APÓS A INDEPENDÊNCIA
}

Para o seu número 41.2, a Remate de Males convidou pesquisadores e estudiosos para refletirem sobre o passado, o presente e o possível devir da literatura brasileira, agora que o país está a ponto de completar 200 anos de independência. $\mathrm{O}$ ano 2022, o número redondo, em si, não representa muito mais do que uma efeméride da autonomia política da nação. A data, porém, pode ser valiosa se nos convidar a uma visão crítica mais ampla e abrangente, visando a um balanço da tradição e de seus futuros possíveis. O que significa essa data para a literatura brasileira? Qual a sua maturidade? Qual a sua organicidade? Quais os seus procedimentos de renovação? A ideia de formação ainda possui atualidade? Estas são apenas algumas das muitas questões que são abordadas e desenvolvidas neste volume.

Atendendo ao convite, o Prof. Jefferson Cano encaminhou o artigo intitulado "A lira da razão: a invenção do romantismo no Rio de Janeiro regencial", no qual afirma que, desde que os primeiros estudos sobre a história da literatura brasileira foram publicados no século XIX, consolidou-se uma interpretação do advento do romantismo como um momento particular no processo de emergência da consciência nacional. Esse artigo argumenta que, no interior das incertezas do contexto brasileiro, o romantismo fornece um conjunto de elementos estéticos que serão apropriados e significados por diferentes grupos.

O Prof. Alfredo César de Melo, no seu artigo "Grande sertão: veredas como ficção de refundação nacional”, revisita as teorias dos três amores desse romance (os amores de Riobaldo por Otacília, Nhorinhá e Diadorim), para analisar o modo como a presença da donzela-guerreira 
(Diadorim) acaba gerando uma situação dramática no desenvolvimento do personagem-narrador da obra, situação esta que questiona o patriarcalismo e acaba por demandar uma outra ordem social à altura do amor alternativo representado por Diadorim.

Também investigando a obra do grande escritor mineiro, Gustavo de Castro Silva, Florence Dravet e Leandro Bessa, no seu artigo “Diadorim sou eu' e o problema biográfico de Guimarães Rosa”, buscam problematizar a expressão "O Diadorim do Grande sertão sou eu” - dita por João Guimarães Rosa a Afonso Arinos e registrada por Josué Montello -, assim como busca circunscrever o problema biográfico do autor mineiro. O texto fundamenta-se na discussão de "crítica biográfica" para fazer a leitura do campo biográfico e da personagem Diadorim. A conclusão aponta para a possibilidade de relacionar fato e ficção à pesquisa e à grande carência de estudos biográficos sobre o autor mineiro.

João Pedro Moura Alves Fernandes, estudando "Os ensaios longos do poeta-crítico Mário Faustino”, considera que este autor raramente é ignorado pelos estudiosos da poesia brasileira dos anos 1950 e da sua crítica. Os poemas do autor e as discussões por ele levantadas na sua página Poesia-Experiência (publicada semanalmente no "Suplemento Dominical" do Jornal do Brasil entre 1956 e 1958) tornaram-se, de fato, tópicos incontornáveis para compreender os debates literários daquele momento. Nesse artigo, Fernandes apresenta a trajetória crítico-criativa de Faustino para, assim, situar e abordar mais detidamente uma parte da obra do autor que merece mais atenção: os ensaios longos, de caráter instrumental e didático, notadamente aqueles compostos como "Diálogos de oficina".

Cleber Vinicius do Amaral Felipe, no seu artigo "Historia magistra vitae e sua (des)continuidade em Pinheiros Chagas", considera que o topos historia magistra vitae, sistematizado por Cícero para afirmar o caráter exemplar e moral da história, foi apropriado por cronistas, historiadores e romancistas portugueses ao longo dos séculos XV-XIX. $\mathrm{O}$ autor pretende avaliar de que maneira a historiografia portuguesa do século XIX retomou preceitos outrora constituintes e definidores da historia magistra vitae, conferindo especial atenção aos escritos de Pinheiro Chagas.

Caion Meneguello Natal, em "Macunaíma e Chico Antônio: heróis do Brasil profundo", considera que Mário de Andrade compreendeu a nação a partir de relações entre pares de opostos: o Brasil seria a imagem híbrida 
entre a cidade e o sertão, o moderno e o arcaico, o progresso e o atraso. Esse artigo questiona o modo como o escritor pensou a identidade brasileira a partir da análise de dois textos: a narrativa clássica Macunaíma e a série de crônicas Vida do cantador, baseada no personagem real Chico Antônio, cantor popular que Mário de Andrade conheceu quando de sua viagem ao Nordeste em fins dos anos 1920. O objetivo então é o de mostrar a construção de uma imagem do Brasil enquanto crítica ou reação à civilização moderna. Em outros termos, segundo o autor, a nação brasileira seria uma civilização nova, dita tropical, avessa ao paradigma de sociedade burguesa europeia.

João Guilherme Dayrell, em "Um estado de cavalos: Guimarães Rosa e Nuno Ramos diante de uma imagem de Euclides da Cunha”, parte da comparação feita por Silviano Santiago, em Genealogia da ferocidade (2017), entre o cavalo mumificado descrito em Os sertões, de Euclides da Cunha, e a figuração deste animal em Grande sertão: veredas (1956), de João Guimarães Rosa, que o crítico usa para recusar qualquer continuidade entre um e outro como o teria feito, finalmente, parte da fortuna crítica roseana. Isso porque o protagonista de Rosa se recusa a ser um "amansador de cavalos". Diferentemente, no livro Ensaio geral (2007), Nuno Ramos reivindica essa mesma imagem do cavalo fossilizado de Os sertões, o que traz consequências não apenas para a figuração do animal no seu posterior Adeus, cavalo (2017), como contamina sua leitura da tradição literária brasileira, a exemplo da ênfase dada à mineralização dos objetos na poesia de João Cabral de Melo Neto.

André Luis Rodrigues, em "Vestígios inapagáveis: a busca pelos desaparecidos políticos na ficção de B. Kucinski”, detém-se na leitura analítico-interpretativa dos livros de ficção de Bernardo Kucinski, K.: relato de uma busca e Os visitantes, que tratam do desaparecimento de Ana Kucinski e de seu marido, Wilson Silva, durante a ditadura militar. O autor propõe que, em lugar da figuração direta da violência desencadeada pelo aparato repressor, a opção do romancista é por uma espécie de recolha dos indícios deixados na esteira dos crimes cometidos em nome do Estado.

Everton Barbosa Correia, no artigo "A predicação de Cardozo nos versos de Cabral", considera que, sendo Joaquim Cardozo o interlocutor mais recorrente ao longo da obra de João Cabral de Melo Neto, é possível visualizar uma série literária entre os poemas que celebram tal diálogo poético. 
O artigo de Pedro Dolabela Chagas e Luiz Guilherme Oliveira, "Viagem e formação: notas sobre o self no romance brasileiro pós-1945, numa leitura de $O$ ventre e $O$ encontro marcado", discute a relação entre o deslocamento espacial e a formação do self nas trajetórias dos protagonistas dos romances de Fernando Sabino e Carlos Heitor Cony, tomados como representantes do Bildungsroman brasileiro dos anos 1950. O objetivo é entender como aquela relação manifestava uma nova imagem do self no nosso romance, em personagens inadaptados aos seus meios de origem e impelidos a processos conflitivos de afirmação existencial.

Eduardo Melo França, com o artigo intitulado "Literatura: da psicologia à forma, do indivíduo a uma realidade mais complexa”, pretende demonstrar que todo gesto mimético empreendido pela literatura, toda forma artística, é também a expressão de um modo de subjetividade, assim como revelador de uma visão de mundo. Tal fato iria se dar principalmente através dos aspectos formais, e não necessariamente discursivos, pois a literatura apreende e representa mais complexamente a realidade, que por sua vez deve ser entendida num sentido mais subjetivo e menos factual. Por fim, conciliando a reafirmação da expressividade formal da literatura a uma concepção mais subjetiva e complexa da realidade, o autor problematiza a possibilidade de a literatura produzir em relação ao mundo um tipo de conhecimento menos conclusivo, assertivo, e muito mais autoirônico, admitidamente paradoxal, inconcluso e metafórico.

\section{LITERATURA ESTRANGEIRA}

Luiz Fernando Ferreira Sá, em "Entre Ovídio e Pessoa: a 'obra perfeita' de John Milton”, sugere que Shakespeare, de acordo com Pessoa, é causa da ausência de construção a que a modernidade está condenada e que passa a caracterizá-la. Dessa forma, Pessoa retoma a figura de Shakespeare como uma imagem da modernidade que a representa no que esta tem de imperfeição construtiva. Poderíamos aproximar a expressão de Pessoa a Milton e considerá-lo um "supra-Ovídio" ou criador de uma "supra-Bíblia”. A escrita de Milton altera o cânone desafiando a auctoritas do texto religioso.

No artigo intitulado "Proust e a busca da cena ausente: o desvio da escrita em A prisioneira e A fugitiva", Francisco Renato de Souza analisa a composição de dois volumes de Em busca do tempo perdido [ $\grave{A} \mathrm{La}$ recherche du temps perdu], de Marcel Proust: A prisioneira [La Prisonnière] 
e A fugitiva [Albertine disparue], como uma derivação do desvio da escrita literária que, por sua vez, é decorrente do desvio do comportamento homossexual de determinados personagens da obra proustiana.

Davi Andrade Pimentel, no artigo intitulado "O relato (ético) de um tradutor de Maurice Blanchot", com base em sua experiência de tradutor deste autor, propõe algumas reflexões sobre a tradução enquanto ato ético, entendendo por ato ético o respeito pela diferença da língua do outro estrangeiro, que significa não aclimatá-la à língua do tradutor, mas sim deixá-la abrir novos espaços sintáticos e semânticos em minha própria língua. Nesse percurso, além da análise da tradução de fragmentos escolhidos da narrativa L'Attente l'oubli, de Blanchot, o autor pretende dialogar com três ideias a seu ver essenciais ao ato tradutório: a primeira, a de Jacques Lacan sobre a letra como materialidade do significante; a segunda, a ideia de Antoine Berman sobre a ética na tradução; e, a terceira, a do próprio Blanchot sobre a tradução enquanto diferença.

\section{RESENHA}

Na resenha "Uma tribo de canibais sai em viagem gastronômica pela Europa" - sobre o livro Cannibal Angels: Transatlantic Modernism and the Brazilian Avant-Garde, do professor de literaturas brasileira e portuguesa na Universidade de Yale, Kenneth David Jackson -, Fabio Waki observa a proposta de rastrear e cartografar as viagens transatlânticas dos modernistas Oswald de Andrade, Mário de Andrade, Tarsila do Amaral, Anita Malfatti, Menotti del Picchia e Heitor Villa-Lobos, valendo-se de um levantamento biográfico e arqueológico das idas, vindas, dos encontros, eventos e das criações que colocaram em contato aqueles artistas que de alguma maneira contribuíram para a organização de uma ideia de antropofagia e, de modo mais amplo, para a mobilização de um efetivo processo de vanguarda modernista brasileira no começo do século XX.

Carlos Eduardo Ornelas Berriel Fabio Akcelrud Durão

Recebido: 20/12/2021

Aceito: 22/12/2021

Publicado: 30/12/2021 